\title{
PENGARUH PEMELIHARAAN TERHADAP PERTUMBUHAN TANAMAN DAN PERMUDAAN ALAM DALAM SISTEM SILVIKULTUR TEBANG RUMPANG
}

The Effects of Silvicultural Treatments on Plants Growth and Natural Regeneration in Gap Cutting Silvicultural System

\author{
Sudin Panjaitan \\ Balai Penelitian dan Pengembangan Lingkungan Hidup dan Kehutanan Banjarbaru, \\ JL. A. Yani Km. 28,7 Landasan Ulin Banjarbaru Kalimantan Selatan; \\ Telepon. (0511) 4707872, Fax (0511) 4707872 \\ Email : sudinpanjaitan@foreibanjarbaru.or.id
}

Diterima : 16 Mei 2016, direvisi : 22 Juni 2016, disetujui : 31 Juli 2016

\begin{abstract}
ABSTRAK
Tebang rumpang merupakan salah satu sistem silvikultur alternatif yang berlandaskan pemudaan alam dengan unit perlakuan tegakan terkecil berupa rumpang-rumpang yang tersusun dalam unit jalan sarad. Sistem tersebut belum teruji secara menyeluruh, termasuk dalam hal pemeliharaan tegakan muda di dalam rumpang. Penelitian dilakukan di KHDTK Kintap, Kalimantan Selatan, dengan tujuan mengetahui pengaruh interaksi pemeliharaan antara lebar pembebasan pohon dengan lama waktu pembebasan terhadap pertumbuhan tanaman Shorea leprosula, anakan alam $S$. parvistipulata, dan Croton graffithii di dalam rumpang. Hasil penelitian menunjukkan bahwa pengaruh interaksi pemeliharaan antara lebar pembebasan dengan waktu pembebasan terhadap pertumbuhan tanaman dan permudaan alam di dalam rumpang secara statistik tidak nyata. Demikian juga pengaruh tunggal dari lebar pembebasan dan frekuensi pembebasan terhadap pertumbuhan tinggi, diameter batang dan tutupan tajuk, secara statistik tidak nyata. Dapat disimpulkan bahwa pemeliharaan khususnya pembebasan tanaman dari gulma tidak mempengaruhi pertumbuhan permudaan. Pertumbuhan tersebut mungkin lebih dipengaruhi oleh kesuburan tanah, intensitas cahaya, temperatur, dan kelembaban di dalam lingkungan rumpang. Kegiatan pemeliharaan 24 bulan setelah rumpang dibuat tidak disarankan.
\end{abstract}

Kata kunci : sistem silvikultur, rumpang, pemeliharaan, tanaman, anakan alam

\section{ABSTRACT}

Gap cutting is one of alternative silvicultural systems that applied based on natural regeneration, which uses gaps formatted in skid trails as smallest treatment unit in tree stands. This system has not been comprehensively studied, including the effects of silvicultural treatments in young stands. This study was conducted in KHDTK Kintap South Kalimantan, aiming at knowing the effects of interaction between the width of gap and duration of treatment on the growth of planted S. leprosula and natural seedlings of S. parvistipulata, as well as Croton graffithii that grow within the gaps. The results showed that the interaction between the width of gap and duration of treatment on plant growth and natural regeneration is not statistically significant. Likewise, the effect of gap width and gap frequency on height and diameter growth, and the width of canopy cover is not statistically significant. In conclusion, silvicultural treatments, especially weeds exemption does not affect the growth of seedlings. The growth may be more influenced by soil fertility, light intensity, temperature, and humidity in the gaps. Silvicultural treatments 24 months after creating gaps are not recommended.

Keywords : silvicultural systems, gaps, tending, plants, natural seedlings

\section{PENDAHULUAN}

\section{A. Latar Belakang}

Hutan merupakan sumberdaya alam yang memegang peranan penting bagi kehidupan dan telah memberikan sumbangan yang berarti bagi perekonomian yaitu sebagai sumber devisa negara dan kesejahteraan masyarakat. Hutan dapat dipandang sebagai mosaik rumpang dari berbagai fase perkembangan dan tingkat umur. Fase perkembangan vegetasi terdiri dari beberapa fase yaitu : 1) fase rumpang (pada saat terjadinya rumpang), 2) fase perkembangan (proses pertumbuhan dan perkembangan vegetasi yang menjadi rumpang), dan 3) Fase tua (vegetasi mencapai klimaks dan kemungkinan mendekati asalnya dan strukturnya berlapis) dimana setiap saat dapat terjadi rumpang yang baru. Fase satu dengan lainnya saling terkait, berkesinambungan dan merupakan suatu proses yang dinamis (Whitmore, 1975).

Pengusahaan hutan alam produksi dengan sistem konsesi hutan di satu pihak telah memberikan kontribusi penting terhadap 
peningkatan devisa dan pertumbuhan ekonomi. Akan tetapi di lain pihak mengakibatkan terjadinya degradasi hutan hutan secara drastis, hal ini terbukti dengan banyaknya terjadi kerusakan tegakan hutan di areal bekas tebangan dimana mencapai 1,6 2,0 juta hektar/tahun (FAO, 2000).

Soerianegara (1971) mengatakan bahwa dalam mengelola hutan alam agar kelestarian produksi dapat tercapai diperlukan adanya pengaturan teknik penebangan dan regenerasi hutan pada suatu sistem silvikultur yang digunakan. Selanjutnya oleh karenanya, kondisi kelompok hutan yang akan dikelola tentu harus sesuai dengan persyaratan yang diinginkan oleh sistem silvikultur yang dipergunakan. Pengelolaan hutan alam produksi yang dikelola oleh konsesi Hak Pengusahaan Hutan (HPH) yang dimulai tahun 1970 dengan menggunakan sistem silvikultur Tebang Pilih Indonesia (TPI). Pada tahun 1989 sistem silvikultur TPI diganti menjadi Tebang Pilih Tanam Indonesia (TPTI) dan revisinya tahun 1993 yaitu berdasarkan Surat Keputusan Direktur Jenderal Pengusahaan Hutan No.: 151/Kpts/IV-BPHH/1993. Pada tahun 2005 dibuat peraturan Menteri Kehutanan Nomor : P.30/Menhut-II/2005 mengenai sistem silvikulur intensif dan akhirnya dicabut kembali keberlakuannya dengan peraturan Menteri Kehutanan Nomor: P.11/MenhutII/2009 tentang Sistem Silvikultur dalam Areal Izin Usaha Pemanfaatan Hasil Hutan Kayu pada Hutan Produksi. Pada peraturan ini ada beberapa hal baru dibandingkan peraturan sebelumnya adalah adanya sistem silvikultur tebang rumpang dan memungkinkan untuk dilaksanakannya lebih dari satu sistem silvikultur yang berbeda pada satu unit pengelolaan hutan produksi.

Sistem tebang rumpang (TR) merupakan hasil kajian dan ujicoba Balai Teknologi Reboisasi Banjarbaru sejak 1985 di Hutan Penelitian Kintap, Kalimantan Selatan. Sistem TR ini sering disebut juga sebagai "Gap Simulation System". Sistem Tebang Rumpang ini berbasis permudaan alami, dan menjadi salah satu sistem yang ditawarkan kepada pemerintah untuk dijadikan suatu sistem silvikultur alternatif untuk pengelolaan hutan alam produksi (Sagala, 1994). Sistem TR ini pada awal pembentukannya dilakukan pada areal hutan yang relatif masih primer, dimana permudaan alami jenis-jenis primer masih tidak menjadi masalah. Pada areal hutan yang telah terfragmentasi berat, TR ini belum diujicoba secara tuntas. Pada saat ini, apakah tebang rumpang berbasis permudaan alami ini masih efekif untuk areal hutan yang telah terfragmentasi. Pertanyaan ini, perlu dijawab melalui serangkaian ujicoba kembali TR di areal hutan yang telah terfragmentasi berat, dimana keberadaan permudaan alami jenis primer menjadi kendala.

Secara umum, apapun sistem silvikutultur yang digunakan pada dasarnya adalah menciptakan ruang-ruang terbuka di dalam hutan. Ruang-ruang terbuka tersebut dapat menjadi suatu triger bagi keberlangsungan proses dinamika hutan yang lebih cepat, tetapi dapat menjadi penghancur keberlangsungan proses dinamika hutan yang ada. Semua itu sangat tergantung dari luas, bentuk dan pola penyebaran ruang terbuka yang tercipta, serta tergantung dari kualitas ruang terbuka bagi perkembangan regenerasi (Brokaw, 1985).

Produktivitas hutan dapat dianggap sebagai laju produksi biomassa yang dihasilkan oleh satu luasan tegakan hutan dalam periode waktu terentu. Dalam konteks hutan produksi, biomass tersebut disederhanakan dalam bentuk volume batang pohon. Produktivitas tersebut merupakan akumulasi dari pertumbuhan pohon dan vegetasi lainnya di dalam hutan. Produktivitas hutan sangat erat hubungannya dengan kelestarian. Kelestarian sumberdaya hutan akan terjaga jika hutan selalu berada dalam tingkat kapasitas produktif maksimum (Fujimori, 2001; Soedomo, 1995). Oleh karena itu, apapun sistem silvikultur yang digunakan dalam suatu kawasan hutan, maka kelestarian akan terjamin jika tetap mampu menjaga level kapasitas produksi maksimum hutan yang bersangkutan. Semua sistem silvikulutur akan selalu mencakup tiga fungsi atau perlakuan dasar, yaitu : (1) permudaan (regeneration), (2) pemeliharaan (tending) dan (3) pemanenan (harvesting). Aplikasi aktual dari semua jenis perlakuan, urutan, tata-waktu kegiatan serta intensitasnya sering berbeda dari satu tegakan hutan ke tegakan lainnya, tergantung dari tujuan pemilik dan kondisi ekologisnya 
(Nayland, 1996). Kesinambungan yang tak terputus dari siklus ketiga fungsi dasar tersebut menjadi kriteria utama keefektifan suatu sistem silvikultur dalam konteks pengelolaan hutan produksi lestari.

Setelah berjalan hampir 40 tahun pengelolaan hutan alam produksi di Indonesia, efektifitas sistem silvikultur yang digunakan tidak mampu melestarikan hutan alam produksi Indonesia. Keberhasilan fungsi regenerasi dan pemeliharaan menjadi kunci keefektifan sistem silvikulutur dalam menuju pengelolaan hutan lestari.

Penelitian bertujuan : untuk mengetahui pengaruh pemeliharaan terhadap pertumbuhan meranti merah ( $S$. leprosula) yang ditanam dan permudaan alam meranti merah $(S$. parvistipulata) dan gamburah (Croton graffithii) pada rumpang buatan.

\section{METODOLOGI PENELITIAN}

Penelitian ini dilakukan di KHDTK Kintap di Desa Riam Adungan Kecamatan Kintap Kalimantan Selatan. Lokasi ini merupakan Eks HPH Hutan Kintap dan saat ini menjadi KHDTK Kintap. Menurut data administrasi pemerintahan daerah, lokasi termasuk dalam Desa Riam Adungan, Kecamatan Kintap, Kabupaten Derah Tingkat II Tanah Laut, Propinsi Kalimantan Selatan. Secara geografis, lokasi berada pada $3^{0} 42^{\prime}$ Lintang Selatan dan $115^{\circ} 9^{\prime}$ Bujur Timur. Jarak dari kota Propinsi (Banjarmasin) berjarak 150 KM dengan arah Tenggara.

Rancangan yang digunakan kedua penelitian ini adalah Rancangan faktorial dalam Rancangan Acak Kelompok (2x2). Faktor pertama adalah waktu pemeliharan (W) yang terdiri atas 2 taraf yaitu Waktu penebasan (W) yang terdiri 2 taraf yaitu: (a) W1 (waktu pemeliharaan tanaman 3 bulan sekali, dan (b) W2 (waktu pemeliharaan tanaman 6 bulan). Faktor kedua ialah radius piringan yang terdiri atas 2 taraf yaitu: (a) D1 (Radius piringan 0,5 $\mathrm{m}$ ), dan D2 (radius piringan 1,0 m).

Kombinasi perlakuan dikelompokan menjadi 2 kelompok. Parameter yang diamati adalah tinggi tanaman, diameter tanaman, lebar tajuk. Selain itu diukur juga intensitas cahaya dan $\mathrm{pH}$ tanah. Kombinasi perlakuan A dan B (waktu dan radius piringan) seperti Tabel 1.

Tabel 1. Kombinasi perlakuan A dan B (waktu pemeliharaan dan radius piringan)

Table 1. Combination between treatment $A$ and $B$ (duration of treatment and width of gaps)

\begin{tabular}{ccc}
\hline Perlakuan & \multicolumn{2}{c}{ Waktu pemeliharaan $(\mathbf{W})$} \\
\hline Radius piringan $(\mathrm{D})$ & $\mathrm{W} 1=3$ bulan sekali & W2 $=6$ bulan sekali \\
\hline $\mathrm{D} 1=0,5 \mathrm{~m}$ & W1D1 & W2D1 \\
\hline $\mathrm{D} 2=1,0 \mathrm{~m}$ & $\mathrm{~W} 1 \mathrm{D} 2$ & W2D2 \\
\hline
\end{tabular}

Bahan dan peralatan yang dipergunakan pada penelitian ini adalah :

1. Bibit tanaman meranti merah dan permudaan alam,

2. Parang,

3. Cangkul,

4. Seigmat,

5. Meteran untuk mengukur tinggi,

6. Lightmeter,

7. Soil tester,

8. Gunting stek,

9. Pita label,

10. Spidol,

11. Cat dan kuas,

12. Tali benang,

13. Tally sheet untuk merekap data,

14. Kamera untuk dokumentasi.
Analisis data dilakukan dengan analisis Variance terhadap variabel yang diamati yaitu tinggi dan diameter tanaman serta lebar tajuk tanaman pada permudaan buatan dan permudaan alam. Sedangkan data intensitas cahaya dan $\mathrm{pH}$ tanah dilakukan dengan analisis deskriptif.

Rumpang dibuat sebanyak 8 buah rumpang dalam satu unit jalan sarad. Ukuran rumpang 1-1,5 kali pohon tepi (radius $\pm 30 \mathrm{~m}$ ). Rumpang dibuat di KHDTK Kintap. Perlakuan silvikultur yang diberikan pada kegiatan awal adalah penanaman meranti pada empat rumpang buatan, sedangkan pada empat rumpang buatan berikutnya perlakuan tanpa tanam yaitu melihat pertumbuhan dan perkembangan permudaan alam. Pada 
penanaman meranti dibuat jarak tanam $2,5 \mathrm{~m}$ di dalam rumpang buatan. Jumlah tanaman disetiap rumpang terdiri 16 batang tanaman. Penanaman meranti merah pada masing- masing rumpang terdiri dari 16 tanaman dengan jarak tanam $2.5 \times 2.5 \mathrm{~m}$, seperti pada Gambar 1.

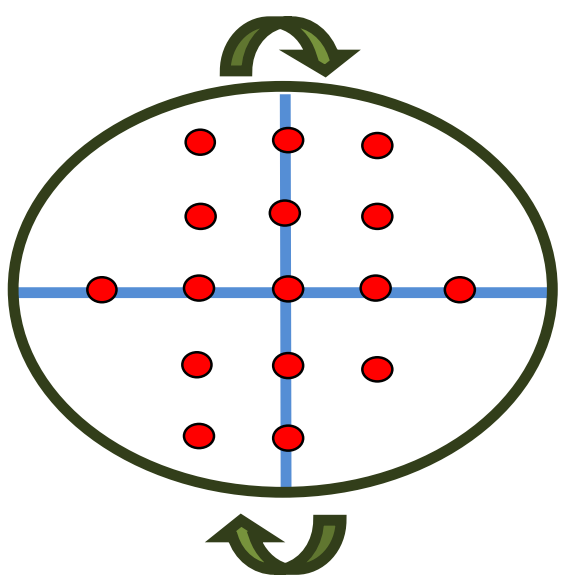

Gambar 1. Arah jalur tanam di dalam rumpang. Bibit ditanam dengan jarak 2.5 x $2.5 \mathrm{~m}$ dari titik tengah sampai tepi rumpang

Figure 1. Planting arrangement in gap cutting system. Planting space is $2.5 \times 2.5 \mathrm{~m}$ started from center point towards gap border

\section{HASIL DAN PEMBAHASAN}

Perlakuan pemeliharaan tanaman meranti merah ( $S$. leprosula) dan $S$. parvistipulata dan permudaan alamnya yang ada di dalam rumpang buatan selama 24 bulan diperoleh hasil bahwa ada pengaruh interaksi yang signifikan, begitu juga waktu pemeliharaan dan radius pemeliharaan tidak bepengaruh yang nyata terhadap diameter tanaman, tinggi tanaman dan lebar tajuk. Data tersebut menujukkan bahwa pertumbuhan tanaman S. leprosula di dalam rumpang lebih ditentukan oleh faktor lainnya selain faktor pemeliharaan. Sebagai contoh faktor kesuburan tanah di dalam setiap rumpang relatif sama. Demikian juga faktor intensitas cahaya, temperatur dan kelembaban relatif sama di dalam rumpang.

Tidak ada pengaruh interaksi, waktu pemeliharaan dan radius piringan yang signifikan terhadap diameter tanaman dan tinggi tanaman, namun terhadap lebar tajuk permudaan alam gamburah (Croton griffithii) terjadi interaksi yang signifikan.

Data pengukuran intensitas cahaya (lux) dan $\mathrm{pH}$ tanah, disajikan pada Tabel 2.

Tabel 2. Intensitas cahaya (lux) dan $\mathrm{pH}$ tanah di masing-masing rumpang buatan

Table 2. Light intensity (lux) and soil $\mathrm{pH}$ in each gap

\begin{tabular}{cccccc}
\hline & Intensitas cahaya (lux $)$ & & \multicolumn{3}{c}{ pH tanah } \\
\hline No. Rumpang & Intensitas cahaya & Rangking & No. Rumpang & pH & Rangking \\
\hline 1 & 10452202 & 5 & 1 & 6.3 & 1 \\
\hline 2 & 1052 & 4 & 2 & 5.7 & 6 \\
\hline 3 & 1227 & 2 & 3 & 6.1 & 3 \\
\hline 4 & 942 & 7 & 4 & 6.2 & 2 \\
\hline 5 & 938 & 8 & 5 & 6.1 & 3 \\
\hline 6 & 2202 & 1 & 6 & 5.9 & 5 \\
\hline 7 & 993 & 6 & 7 & 6.2 & 2 \\
\hline 8 & 1066 & 3 & 8 & 6.0 & 4 \\
\hline
\end{tabular}

Sumber : diolah dari data primer

Dari Tabel 2 tersebut di atas, tampak bahwa intensitas cahaya menunjukkan adanya variasi dimana yang tertinggi (rangking 1) sebesar 2.202 terjadi pada rumpang 6 dan 
terendah (rangking 8) senilai 938 terdapat pada rumpang 5. Sedangkan $\mathrm{pH}$ tanah tertinggi (rangking 1) sebesar 6.3 terjadi pada rumpang 1 dan terendah sebesar 5.7 terjadi pada rumpang 2 .
Berdasarkan uji $t$ bahwa kondisi intensitas cahaya dan $\mathrm{pH}$ tanah antar masingmasing rumpang berbeda sangat nyata ditandai dengan nilai $\mathrm{t}=7,9$ dan 89,118 dalam signifikansi 0,00 yang berarti berbeda sangat nyata (Tabel 3 ).

Tabel 3. Uji t terhadap intensitas cahaya antar masing-masing rumpang

Table 3. $t$-test on light intensity between gaps

\begin{tabular}{lccc}
\multicolumn{1}{c}{ Variabel } & t & df & Sig. \\
\hline Intensitas Cahaya & 7,937 & 7 & 0,00 \\
\hline $\mathrm{pH}$ tanah & 89,118 & 7 & 0,00 \\
\hline
\end{tabular}

Sumber : diolah dari data primer

Tempat tumbuh suatu jenis vegetasi sangat kompleks dan merupakan hasil interaksi dari berbagai faktor. Setia Budi Peran (1984) mengatakan bahwa bahwa baik macam maupun suatu vegetasi yang dihasilkan persatuan areal, berkorelasi dengan faktorfaktor tempat tumbuh. Selanjutnya disebutkan faktor tempat tumbuh yang baik yang dapat berpengaruh langsung maupun tidak lansung dibagi dalam empat (4) golongan yaitu : 1) faktor klimatis, 2) edafis, 3) fisiografis, dan 4) biotis.

Sagala (1998) mengemukakan bahwa faktor tempat tumbuh memiliki unsur yang cukup banyak dimana saling mempengaruhi antara satu dengan lainnya. Selanjutnya disebutkan secara praktis di lapangan faktor tempat tumbuh dibagi ke dalam 3 kelompok. Pertama, faktor tempat tumbuh yang berada di atas tanah yakni : 1) pohon nungan atas, 2) pohon naungan samping, 3) ukuran gap/rumpang, 4) intensitas cahaya, 5) lamanya penyinaran, 6) temperatur udara, dan 7) kelembaban udara. Kedua, faktor tempat tumbuh yang berada dipermukaan tanah yakni : 1) jenis gulma, 2) kerapatan gulma, 3) seresah, 4) kelerengan, 5) mikro organisme, dan 6) fauna. Ketiga, faktor tempat tumbuh yang berada di dalam tanah yaitu : 1) ketebalan tanah, 2) kegemburan tanah, 3) kandungan unsur hara, 4) $\mathrm{pH}$ tanah, 5) bahan orgaanik, 6) mikorisa, 7) suhu tanah, 8) jenis tanah, dan 9) rhizobium.

Kondisi kesuburan tanah pada masingmasing rumpang dijadikan menjadi bahan penunjang pembahasan pada saat analisis hasil pertumbuhan tanaman dan anakan alam telah dilakukan. Dari hasil analisa tanah yang dilakukan tampak bahwa $\mathrm{pH}$ tanah di masingmasing rumpang tergolong rendah (kondisi masam) dan KTK pada rumpang 1,2,3,4,5,6 dan 8 tergolong tinggi, sedangkan pada rumpang 7, KTK sangat tinggi dengan nilai $45,00 \quad(\mathrm{cmol}(+) / \mathrm{kg}$. Sedangkan P2O5 pada masing-masing rumpang sangat rendah, dan $\mathrm{K} 2 \mathrm{O}$ tergolong rendah sampai sangat rendah. Hasil identifikasi jenis bahwa ditemukan ada 55 jenis vegetasi yang berada di plot penelitian dan hasilnya disajikan pada Tabel 14 (terlampir).

\section{KESIMPULAN DAN SARAN}

1. Pengaruh perlakuan tunggal baik radius piringan dan waktu pemeliharaan tidak nyata terhadap pertumbuhan tinggi, diameter dan lebar tajuk meranti merah $(S$. leprosula), permudaan alam meranti merah (S. parvistipulata) dan gamburah (Croton graffithii).

2. Pengaruh interaksi perlakuan radius piringan dan waktu pemeliharaan baik 3 bulan sekali dan 6 bulan sekali tidak nyata terhadap pertumbuhan tinggi, diameter dan lebar tajuk meranti merah ( $S$. leprosula), permudaan alam meranti merah $(S$. parvistipulata) dan gamburah (Croton graffithii).

3. Pertumbuhan baik tanaman meranti merah (S. leprosula) maupun permudaan alam meranti merah ( $S$. parvistipulata) dan gamburah (Croton graffithii) di dalam rumpang buatan lebih dipengaruhi oleh faktor lain selain pemeliharaan. Faktor tersebut diduga antara lain kesuburan tanah, 
intensitas cahaya, temperatur, dan kelembaban di dalam lingkungan rumpang.

4. Aplikasi sistem silvikultur tebang rumpang (TR) dimana setelah rumpang dibuat, maka pemeliharaan tanaman meranti merah $(S$. leprosula) dan permudaan alam meranti merah (S. parvistipulata) dan gamburah (Croton graffithii) yang tumbuh dalam dalam rumpang tidak perlu dilakukan pemeliharaan, seleksi dan dominasi jenis pada setiap tempat tumbuh akan berlangsung secara alami.

5. Diperlukan penelitian lebih lanjut untuk mengetahui pengaruh faktor cuaca seperti temperatur, kelembaban, dan intensitas cahaya yang diduga berpengaruh lebih kuat daripada pemeliharaan tanaman $S$. leprosula maupun permudaan alam $S$. parvistipulata dan Croton graffithii.

\section{DAFTAR PUSTAKA}

Brokaw, N.V., (1985). Treefals, Regrowth, and Community Structure in Troomi Forests. In: Pickett S.T.A. and P.S. Whde (editors): The Ecology of Natural Disturbance and Patch Dynamics. Academic Press Inc. Odarbdo, F . p 53-69

FAO, (2000). The Global Forest Resources Assesment 2000. Rome Italy. Summery

Report.

Nayland, R.D., (1996). Silviculture. Concepts and Applications. McGraw-Hill Co. Inc. New York. : 632.

Panjaitan, S., dan Supriadi, (1997). Balai Teknologi Reboisasi Banjarbaru. Penggunaan Kuvio Bentuk Rumpang di Areal Tebangan Hutan Perbukitan di Kintap : Pembuatan Kuvio dan
Register Tegakan Rumpang. Desain Lapangan Unit Pengelolaan Hutan Produksi Lestari (unit PHPL)" Menggunakan Kuvio Bentuk Rumpang Di Semua Tipe Hutan dan Kondisi Tegakan. Materi Ekspose Di Departemen Kehutanan.

Sagala, A.P.S., (1989). Memanfaatkan dan Melestarikan Hutan Produksi Indonesia. Departemen Kehutanan Ditjen Reboisasi dan Rehabilitasi Lahan. Balai Teknologi Reboisasi Banjarbaru. $324 \mathrm{p}$.

Sagala, A.P.S., (1994). Mengelola Lahan Kehutanan Indonesia. Yayasan Obor Indonesia, Jakarta.

Sagala, A.P.S., (1998). Pengelolaan Hutan Alam Meranti. Departemen Kehutanan. Balai Teknologi Reboisasi, Banjarbaru.

Setia Budi Peran, (1984). Suksesi pada Hutan Alam Sekunder di Daerah Hutan Pendidikan Fakultas Kehutanan Universitas Lambung Mangkurat, Banjarbaru. Skripsi Fakultas Kehutanan Unlam, Banjarbaru. (Tidak dipublikasikan).

Soerianegara, I. (1971). Sistem-sistem Silvikultur untuk Hutan Hujan Tropika di Indonesia. Rimba Indonesia 15 (3-4) : 83-93.

Soerianegara, I., dan Indrawan, A., (1988). Ekologi Hutan Indonesia. Laboratorium Ekologi Hutan, Fakultas Kehutanan, Institut Pertanian Bogor, Bogor. : 136.

Whitmore, T.C. ,(1975). Tropical Rain Forest of The Far East. Clarendon Press, Oxford. 
Lampiran : Hasil identifikasi jenis di plot penelitian, disajikan pada Tabel 4 berikut :

Tabel 4. Hasil identifikasi jenis yang terdapat di plot penelitian (55 specimen)

Table 4. List of species found in research plot ( 55 specimens)

\begin{tabular}{|c|c|c|c|}
\hline No. & Nama lokal & Genus & Family \\
\hline 1. & Kayu pagar & Ficus sp. & Moraceae \\
\hline 2. & Bayur & Pterospermum javanicum Jungh. & Sterculiaceae \\
\hline 3. & Maritam & Nephelium unicatum Radlk. Ex. Leenh. & Sapindaceae \\
\hline 4. & Kunjajing & Ficus sp. & Moraceae \\
\hline 5. & Kuringkai & Spatiostemon javensis Blume & Euphorbiaceae \\
\hline 6. & Jambukan & Ptychopyxis arborea (Merr.) Airy Shaw & Euphorbiaceae \\
\hline 7. & Mawai & Cleistanthus $\mathrm{sp}$ & Euphorbiaceae \\
\hline 8. & Mahirangan & Diospyros sp. & Ebenaceae \\
\hline 9. & Miranja & Xanthophyllum affine Korth. Ex Miq. & Polygalaceae \\
\hline 10. & Keramaian & Baccaurea tetrandra Mull. Arg. & Euphorbiaceae \\
\hline 11. & Dandalin & Ficus obscura Blume & Moraceae \\
\hline 12. & Ruhut & Syzygium sp. & Myrtaceae \\
\hline 13. & Empadu puyao & Hydnocarpus woodii Merr. & Flacourtiaceae \\
\hline 14. & Timbun habu & Gironniera nervosa Planch. & Ulmaceae \\
\hline 15. & Kayu buluh & Ochanostachys amentaceae Mast. & Euphorbiaceae \\
\hline 16. & Kayu kelapaan & Mallotus penangensis Mull. Arg. & Euphorbiaceae \\
\hline 17. & Kumbayau & Dacryodes rostata (Blume) H.J.Lam & Burseraceae \\
\hline 18. & Kepayang baiy & Ryparosa kostemansii Sleumer & Flacourtiaceae \\
\hline 19. & Belayang & Aglaia tomentosa Teijsm. \& Bennett & Meliaceae \\
\hline 20. & Kayu karang & Dipterocarpus stellatus Vesque & Dipterocarpaceae \\
\hline 21. & Kunidai & Uvaria sp. & Annonaceae \\
\hline 22. & Upas taang & Mallotus mollissimus (Geiseler) Airy Shaw & Euphorbiaceae \\
\hline 23. & Pisang-pisang & Enicosanthum paradoxum Becc. & Annonaceae \\
\hline 24. & Giang-giang & Leea indica (Burm. f) Merr. & Leeaceae \\
\hline 25. & Gamburah daun besar & Croton griffithii Hook.f. & Euphorbiaceae \\
\hline 26. & Kahingai & Canarium odontophyllum Miq. & Burseraceae \\
\hline 27. & Kayu kantut & Urophyllum sp. & Rubiaceae \\
\hline 28. & Tantapung & Callicarpa glabrifolia A. Atkins & Verbenacea \\
\hline 29. & Masira & Ziziphus angustifolius (Miq.) Hatusima ex Steenis & Rhamnaceae \\
\hline 30. & Siah-siah & Urophyllum arborescens & Rubiaceae \\
\hline 31. & Kalangkala & Litsea garciae Vidal & Lauraceae \\
\hline 32. & Madang jubung-jubung & Litsea ferruginea Blume & Lauraceae \\
\hline 33. & Sinampar & Dialium indum Leen. & Leguminosae \\
\hline 34. & Kumpat & Lithocarpus sp. & Fagaceae \\
\hline 35. & Kayu burai & Garcinia beccarii Pierre & Guttiferae \\
\hline 36. & Kayu tanpa laho & Buchanania sessifolia Blume & Anacardiaceae \\
\hline 37. & Kaluntan & Artocarpus elasticus Blume & Moraceae \\
\hline 38. & Kuminjah & Memecylon edule Roxb. & Melastomataceae \\
\hline 39. & Pakan & Croton argyratus Blume & Euphorbiaceae \\
\hline 40. & Margatahan & Palaquium sericeum H.J.Lam & Sapotaceae \\
\hline 41. & Keminting rantau & Scaphium macropodum & Sterculiaceae \\
\hline 42. & Susumpit & Melicope glabra (Blume) T.G. Gartley & Rutaceae \\
\hline 43. & Injamdahan & Ardisia sp. & Myrsinaceae \\
\hline 44. & Tampar badak & Tabernaemontana macrocarpa Korth. Ex Blume & Apocynaceae \\
\hline 45. & Wawangun & Melicope glabra (Blume) T.G. Hartley & Rutaceae \\
\hline 46. & Baitis & Palaquium stenophyllum H.J.Lam & Sapotaceae \\
\hline 47. & Bungka & Sterculia macrophylla Vent. & Sterculiaceae \\
\hline 48. & Bindrih & Ericybe glomerata Blume & Convolvulaceae \\
\hline 49. & Putat & Planchonia valida (Blume) Blume & Lecythidaceae \\
\hline 50. & Kayu saru & Heliciopsis artocarpoides (Elmer) Sleumer & Proteaceae \\
\hline 51. & Kambukan & Chisocheton sp. & Meliaceae \\
\hline 52. & Singkuang raho & Dracontomelon dao (Blanco) Merr. \& Rolfe & Meliaceae \\
\hline 53. & Paning-paning & Lithocarpus gracilis (Korth.) Soepadmo & Fagaceae \\
\hline 54. & Timpasu & Beccaurea lanceolata (Miq.) Mull.Arg. & Euphorbiaceae \\
\hline 55. & Gamburah daun kecil & Mallotus sp. & Euphorbiaceae \\
\hline
\end{tabular}

Sumber : Balai Penelitian Teknologi Konservasi Sumber Daya Alam Samboja Kalimantan Timur, 2013 
Dokumentasi kegiatan dan tanaman

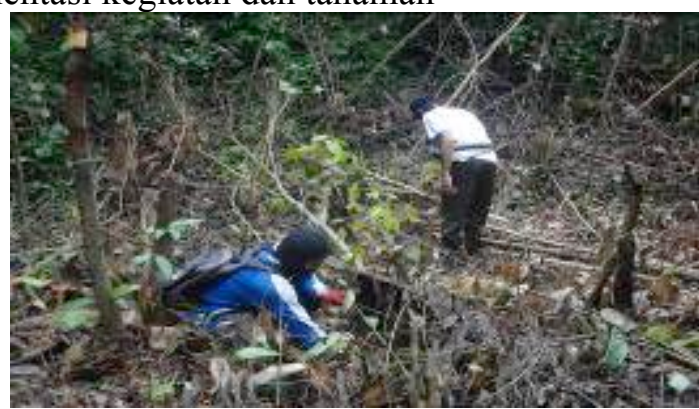

Pengukuran tanaman

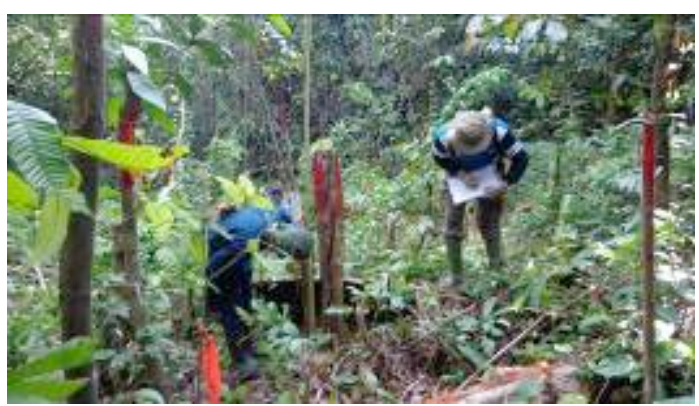

Pengukuran permudaan alam

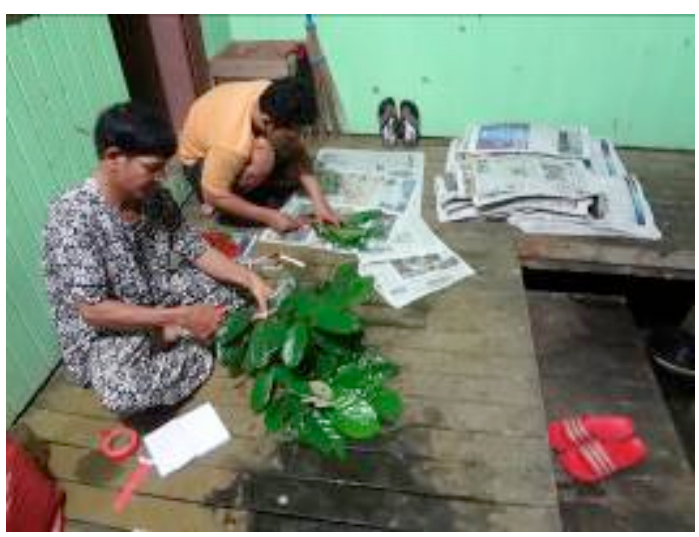

Kegiatan Pembuatan herbarium

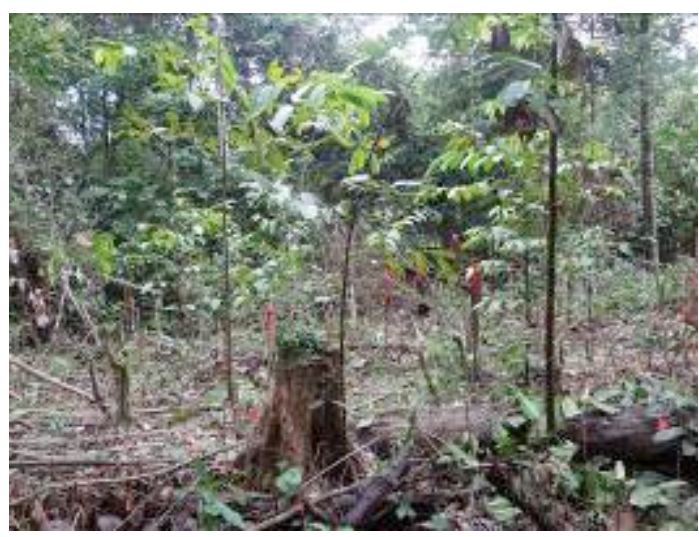

Permudaan alam

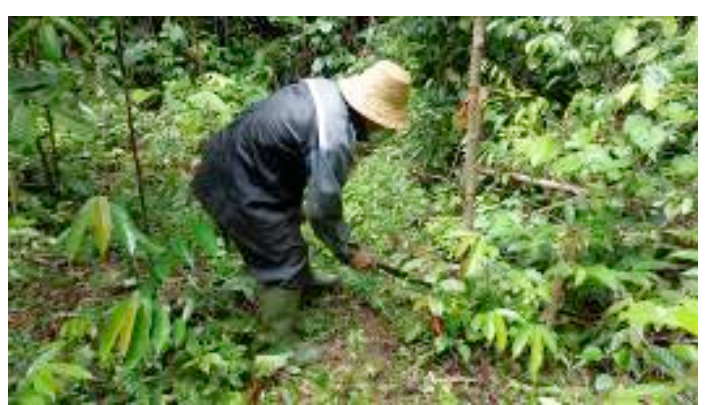

Pemeliharaan permudaan alam

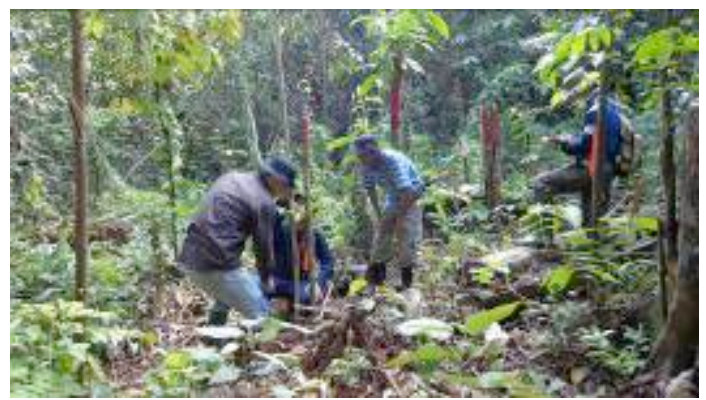

Pengukuran permudaan alam

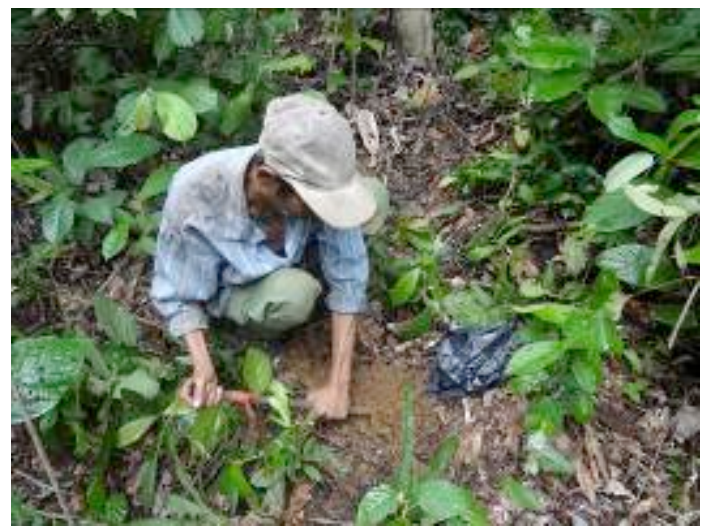

Pengambilan sampel tanah

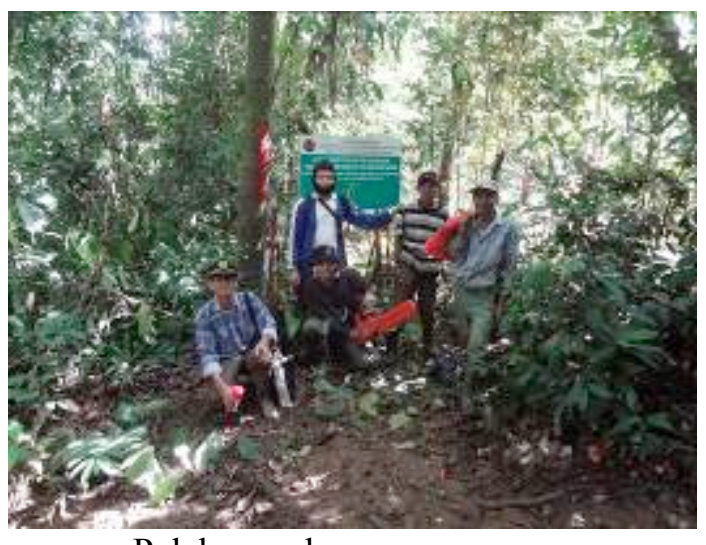

Pelaksana dan papan nama 